\title{
Evaluation of exposures at a coffee roasting, flavoring, and packaging facility
}

\section{Alyson R. Fortner, MPH, PhD Michael C. Beaty}

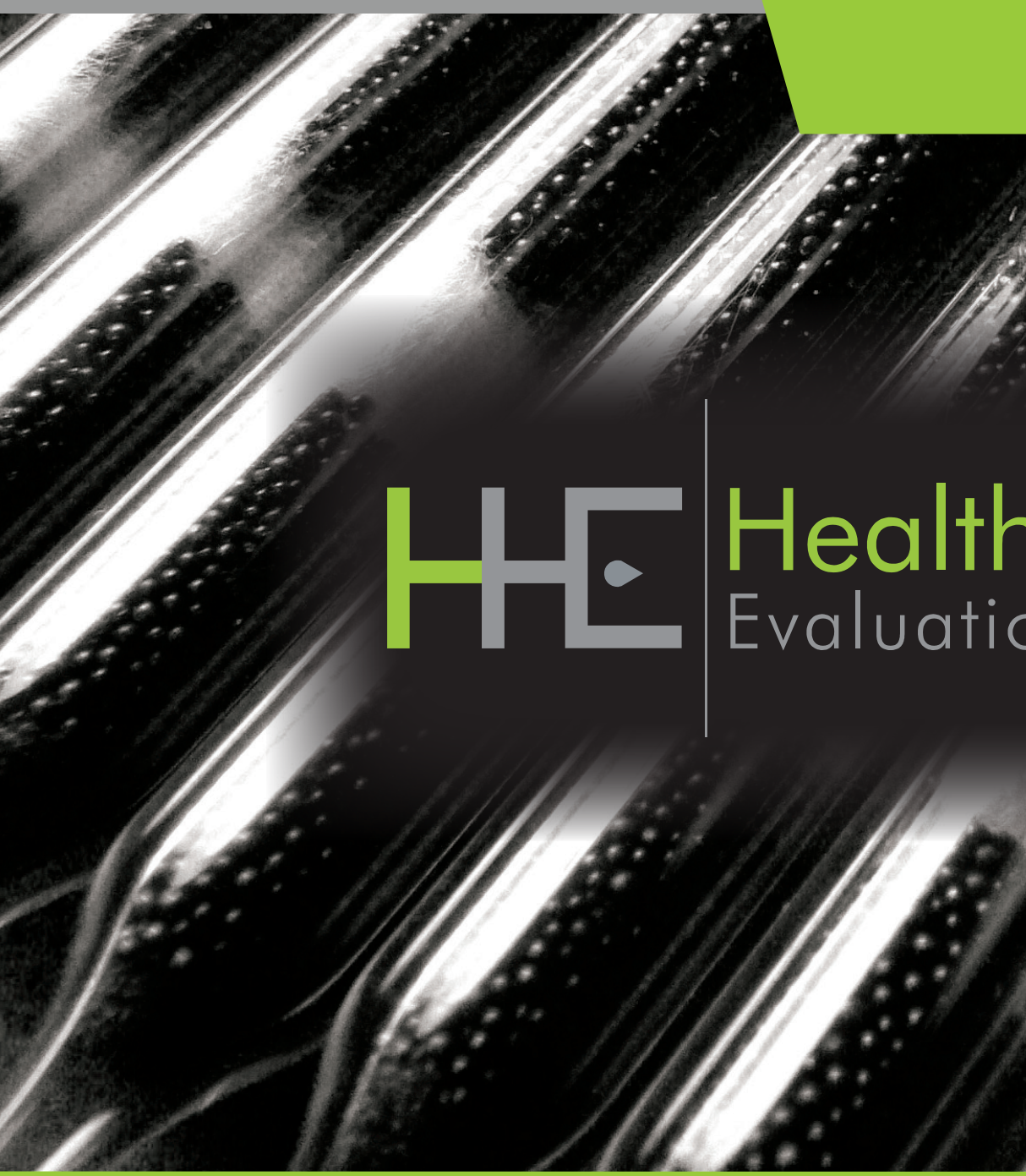

Report No. 2018-0134-3373

April 2020

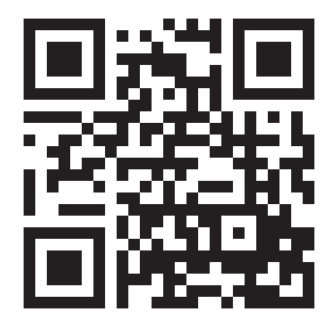

U.S. Department of Health and Human Services Centers for Disease Control and Prevention

National Institute for Occupational Safety and Health

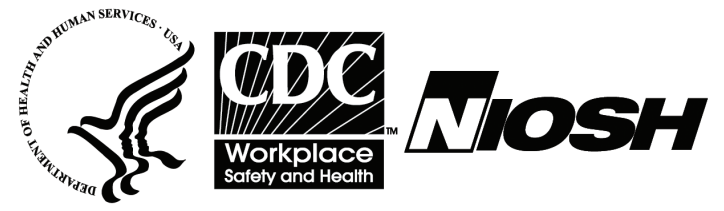




\section{Contents}

Highlights................................................... i

Abbreviations ....................................... 1

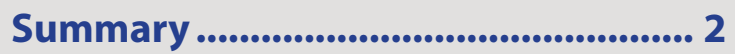

Introduction ........................................... 2

Background............................................. 2

Process Description ............................... 4

Methods ............................................. 5

Results .................................................... 8

Discussion ........................................... 10

Conclusions ...................................... 13

Recommendations............................ 13

Appendix A: Tables.............................. 18

References............................................. 25

Acknowledgements......................... 32

The employer is required to post a copy of this report for 30 days at or near the workplace(s) of affected employees. The employer must take steps to ensure that the posted report is not altered, defaced, or covered by other material.

The cover photo is a close-up image of sorbent tubes, which are used by the HHE Program to measure airborne exposures. This photo is an artistic representation that may not be related to this Health Hazard Evaluation. 


\section{Highlights of this Evaluation}

The Health Hazard Evaluation Program of the National Institute for Occupational Safety and Health received a request from management at a coffee roasting, flavoring, and packaging facility regarding concerns about potential health effects from exposure to diacetyl, 2,3-pentanedione, and other alpha-diketones during coffee roasting, grinding, and flavoring of coffee.

\section{What We Did}

- We visited the coffee roasting, flavoring, and packaging facility during April 2019.

- We collected full-shift (hours), task (minutes), and instantaneous (seconds) air samples to measure concentrations of diacetyl, 2,3-pentanedione, and 2,3-hexanedione.

- We measured real-time air levels of total volatile organic compounds, carbon monoxide, and carbon dioxide.

\section{What We Found}

- All (13 of 13) personal full-shift air sampling concentrations of diacetyl and 2,3-pentanedione exceeded the recommended exposure limit of 5 parts per billion for diacetyl or 9.3 parts per billion for 2,3-pentanedione. The highest measured exposures were 185.4 parts per billion for diacetyl on a grinder operator and 279.9 parts per billion for 2,3-pentanedione on a packaging operator.

- Short-term personal air sampling concentrations of diacetyl and 2,3-pentanedione were higher for tasks involving flavoring coffee (maximum 208.4 parts per billion diacetyl and 1,150 parts per billion 2,3-pentanedione) and packaging roasted coffee (maximum 178.8 parts per billion diacetyl and 245.2 parts per billion 2,3-pentanedione). All (11 of 11) 15-minute personal air sampling concentrations exceeded the NIOSH short-term exposure limit of 25 parts per billion for diacetyl and 31 parts per billion for 2,3-pentanedione.

- Instantaneous air samples, collected at the grinder dispenser while unflavored coffee was

We evaluated the airborne exposures to the alpha-diketones diacetyl, 2,3-pentanedione, and 2,3-hexanedione, other volatile organic compounds, carbon monoxide, and carbon dioxide among employees at a coffee roasting, flavoring, and packaging facility. Employees had personal fullshift exposures that exceeded the $\mathrm{NIOSH}$ recommended exposure limit for diacetyl or 2,3-pentanedione. Personal air sampling during shortterm tasks identified grinding roasted coffee beans, flavoring coffee, and packaging roasted coffee as tasks with higher exposures to alpha-diketones than other tasks. All short-term air sampling during roasting, grinding, flavoring, and packaging exceeded the recommended short-term exposure limit for diacetyl or 2,3-pentanedione (25 parts per billion and 31 parts per billion). Continuous air sampling for carbon monoxide identified peak exposures during grinding of roasted coffee and full-shift exposures above the action level for all employees sampled. We recommend training employees about workplace hazards. We also recommend installing local exhaust ventilation at the grinders to reduce exposures to diacetyl, 2,3-pentanedione, and carbon monoxide. Finally, we recommend providing respiratory protection for diacetyl and 2,3-pentanedione to reduce exposures to alpha-diketones until engineering and administrative controls are in place. 
ground, had maximum concentrations of 2,463 parts per billion for diacetyl and 2,067 parts per billion for 2,3-pentanedione.

- All (10 of 10) full-shift personal concentrations for carbon monoxide were below the NIOSH recommended exposure limit of 35 parts per million, but all measurements exceeded the action level of 17.5 parts per million. A grinder operator had a single personal carbon monoxide measurement of 234 parts per million, which exceeded the NIOSH ceiling limit of 200.

\section{What the Employer Can Do}

- Ensure employees understand potential hazards (e.g., diacetyl, 2,3-pentanedione, carbon monoxide, carbon dioxide, and green and roasted coffee dust) in the workplace and how to protect themselves.

- Ensure the exhaust fan in the flavoring area is always turned on whenever flavoring tasks are performed to improve ventilation.

- Install local exhaust ventilation at the grinders to reduce air concentrations of alphadiketones (diacetyl and 2,3-pentanedione) and carbon monoxide during grinding of roasted coffee.

- Make N95 disposable filtering-face piece respirators available for voluntary use for protection against dust exposure when emptying burlap bags of green beans, cleaning the exhaust system of chaff, emptying the chaff containers, or cleaning the green bean storage area. N95 disposable filtering-face piece respirators do not provide respiratory protection against diacetyl, 2,3-pentanedione, or other alpha-diketones.

- Provide respiratory protection for diacetyl and 2,3-pentanedione to reduce exposures to alpha-diketones until engineering and administrative controls are in place.

- Encourage employees to report new, worsening, or ongoing respiratory symptoms to their personal healthcare providers and to a designated individual at the workplace.

- Institute a medical monitoring program for all employees who work in or enter areas where coffee is flavored. Employees who work in or enter these areas for 40 or more hours per year should be included in the medical monitoring program.

\section{What Employees Can Do}

- Use local exhaust ventilation as instructed by your employer after it is installed.

- Some employees might wish to use N95 disposable filtering-facepiece respirators when emptying burlap bags of green beans, when cleaning the exhaust system of chaff, when emptying the chaff containers, or when cleaning the green bean storage area.

- Report new, persistent, or worsening respiratory symptoms to your healthcare providers and, as instructed, to a designated individual at your workplace.

- Participate in your employer's medical monitoring program as instructed by your employer.

- If you smoke, participate in a smoking cessation program. For more information, please visit https://www.cdc.gov/tobacco/quit smoking/index.htm. 
This page left intentionally blank 


\section{Abbreviations}

$\mathrm{ACGIH}^{\circledR} \quad$ American Conference of Governmental Industrial Hygienists

CFR Code of Federal Regulations

$\mathrm{CO} \quad$ Carbon monoxide

$\mathrm{CO}_{2} \quad$ Carbon dioxide

IDLH Immediately dangerous to life or health

LOD Limit of detection

$\mathrm{mL} \quad$ Milliliter

$\mathrm{mL} / \mathrm{min} \quad$ Milliliter per minute

NIOSH National Institute for Occupational Safety and Health

OEL Occupational exposure limit

OSHA Occupational Safety and Health Administration

PEL Permissible exposure limit

ppb Parts per billion

ppm Parts per million

QC Quality control

REL Recommended exposure limit

$\mathrm{RH} \quad$ Relative humidity

STEL Short-term exposure limit

TLV $^{\circledR} \quad$ Threshold limit value

TWA Time-weighted average

VOC Volatile organic compound 


\section{Summary}

The Health Hazard Evaluation Program of the National Institute for Occupational Safety and Health received a request from management at a coffee roasting, flavoring, and packaging facility regarding concerns about potential health effects from exposure to diacetyl, 2,3-pentanedione, and other alpha-diketones during coffee roasting, grinding, and flavoring of coffee. In April 2019, we conducted an industrial hygiene survey at the facility. The industrial hygiene survey consisted of the collection of air samples for the analysis of diacetyl, 2,3-pentanedione, and 2,3-hexanedione. We used continuous monitoring instruments to monitor total volatile organic compounds, carbon monoxide, and carbon dioxide in specific areas and during tasks.

All full-shift personal samples collected during the industrial hygiene survey exceeded the recommended exposure limits of 5 parts per billion for diacetyl or 9.3 parts per billion for 2,3-pentanedione in 13 of 13 samples. Grinding roasted coffee beans, flavoring roasted beans, and packaging roasted coffee beans resulted in relatively higher air concentrations of diacetyl and 2,3-pentanedione than other tasks. We observed high instantaneous levels of diacetyl and 2,3-pentanedione during grinding of unflavored coffee. Continuous air sampling for carbon monoxide identified peak exposures during grinding of roasted coffee. Area carbon monoxide measurements were higher near the main grinder and in the roasted bean storage/off-gassing and staging area compared with other work areas. Carbon dioxide levels were below occupational exposure limits throughout the facility. We recommend implementing local exhaust ventilation on the grinders, and training employees about workplace hazards. We also recommend providing respiratory protection for diacetyl and 2,3-pentanedione to reduce exposures to alpha-diketones until engineering and administrative controls are in place.

\section{Introduction}

The National Institute for Occupational Safety and Health (NIOSH) received a management request for a health hazard evaluation at a coffee roasting, flavoring, and packaging facility regarding potential employee exposure to diacetyl during coffee processing. In April 2019, we conducted an industrial hygiene survey at the facility. We collected area and personal breathing zone air samples for volatile organic compounds (VOCs), including diacetyl, 2,3-pentanedione, and 2,3-hexanedione. We also monitored and recorded total VOCs, carbon monoxide $(\mathrm{CO})$, and carbon dioxide $\left(\mathrm{CO}_{2}\right)$.

\section{Background}

The National Institute for Occupational Safety and Health (NIOSH) received a management request for a health hazard evaluation at a coffee roasting, flavoring, and packaging facility regarding potential employee exposure to diacetyl during coffee processing. In April 2019, we conducted an industrial hygiene survey at the facility. We collected area and personal breathing zone air samples for volatile organic compounds (VOCs), including diacetyl, 
2,3-pentanedione, and 2,3-hexanedione. We also monitored and recorded total VOCs, carbon monoxide $(\mathrm{CO})$, and carbon dioxide $\left(\mathrm{CO}_{2}\right)$.

Table 1. Exposure limits for compounds sampled during the NIOSH survey, April 2019

\begin{tabular}{|c|c|c|c|c|c|c|}
\hline \multirow{2}{*}{ Compound } & OSHA $^{*}$ & \multicolumn{2}{|c|}{ ACGIH } & \multicolumn{3}{c|}{ NIOSH } \\
\cline { 2 - 7 } & PEL & TLV & STEL & REL & STEL & IDLH \\
\hline Diacetyl & - & $10 \mathrm{ppb}$ & $20 \mathrm{ppb}$ & $5 \mathrm{ppb} \dagger$ & $25 \mathrm{ppb}$ & - \\
\hline 2,3-Pentanedione & - & - & - & $9.3 \mathrm{ppb} \dagger$ & $31 \mathrm{ppb}$ & - \\
\hline 2,3-Hexanedione & - & - & - & - & - & - \\
\hline Carbon dioxide + & $5,000 \mathrm{ppm}$ & $5,000 \mathrm{ppm}$ & $30,000 \mathrm{ppm}$ & $5,000 \mathrm{ppm}$ & $30,000 \mathrm{ppm}$ & $40,000 \mathrm{ppm}$ \\
\hline $\begin{array}{c}\text { Carbon } \\
\text { monoxide }\end{array}$ & $50 \mathrm{ppm}$ & $25 \mathrm{ppm}$ & - & $35 \mathrm{ppm}$ & $\begin{array}{c}200 \mathrm{ppm} \\
\text { (ceiling limit) } \S\end{array}$ & $1,200 \mathrm{ppm}$ \\
\hline
\end{tabular}

Note: OSHA=Occupational Safety and Health Administration; ACGIH=American Conference of Governmental Industrial Hygienists; NIOSH=National Institute for Occupational Safety and Health; PEL=permissible exposure limit; STEL=shortterm exposure limit; $T L V=$ threshold limit value; $R E L=$ recommended exposure limit; IDLH=immediately dangerous to life or health; ppb=parts per billion; ppm=parts per million; "_"=no exposure limit available.

*There are no OSHA STEL values for the compounds in the table.

$\uparrow$ The NIOSH RELs for diacetyl and 2,3-pentanedione are time-weighted averages for up to an 8-hour day, during a 40-hour workweek.

\$OSHA and NIOSH limits are designed for occupational exposure measurements in manufacturing and other trades that have potential sources of carbon dioxide or carbon monoxide (e.g., coffee roasting, welding, vehicle exhaust, diesel engine exhaust). Typical levels of carbon monoxide in offices are $0-5 \mathrm{ppm}$. In office settings, carbon dioxide generally should not be greater than $700 \mathrm{ppm}$ above outdoor carbon dioxide levels; this typically corresponds to indoor concentrations below 1,200 ppm.

$\S$ This is the NIOSH ceiling exposure limit for carbon monoxide. A ceiling concentration should not be exceeded at any time

\section{Obliterative Bronchiolitis}

Obliterative bronchiolitis is a serious, often disabling, lung disease that involves scarring of the small airways (i.e., bronchioles). Symptoms of this disease can include cough, shortness of breath on exertion, or wheeze, that do not typically improve away from work [NIOSH 2012]. Occupational obliterative bronchiolitis has been identified in flavoring manufacturing workers and microwave popcorn workers who worked with flavoring chemicals or butter flavorings [Kreiss 2013; Kim et al. 2010; Kanwal et al. 2006]. Obliterative bronchiolitis has also been identified among employees at a coffee roasting and packaging facility that produced unflavored and flavored coffee [CDC 2013]. A NIOSH health hazard evaluation at that facility found diacetyl and 2,3-pentanedione concentrations in the air that were elevated (range: $4.3 \mathrm{ppb}$ to $166 \mathrm{ppb}$ diacetyl; $<5.2 \mathrm{ppb}$ to $199 \mathrm{ppb} 2,3$-pentanedione) and identified three sources: 1) flavoring chemicals added to roasted coffee beans in the flavoring area; 2) grinding unflavored roasted coffee beans and packaging unflavored ground and whole bean roasted coffee in a distinct area of the facility, and 3) storing roasted coffee in hoppers for off-gassing, on a mezzanine above the grinding/packaging process [Duling et al. 2016]. At the time of the previous health hazard evaluation, employees had excess shortness of breath and obstruction on spirometry, both consistent with undiagnosed lung disease. Respiratory illness was associated with exposure and not limited to the flavoring areas [Bailey et al. 2015]. However, all employees who were diagnosed with obliterative bronchiolitis had worked in the flavoring area. Recently, obliterative bronchiolitis was reported in an individual in India who had worked for 20 years in a coffee facility that roasted and ground coffee and was not known to use added flavorings; he quit after developing respiratory symptoms [Chetambath et al. 2020]. 


\section{Work-related Asthma}

Work-related asthma refers to asthma that is brought on by ("occupational asthma") or made worse by ("work-exacerbated asthma" or "work-aggravated asthma") workplace exposures [Tarlo 2016; Tarlo and Lemiere 2014; OSHA 2014; Henneberger et al. 2011; NIOSH 2017]. It includes asthma attributable to sensitizers, which cause disease through immune (allergic) mechanisms, and asthma attributable to irritants, which cause disease through non-immune mechanisms. Symptoms of work-related asthma include episodic shortness of breath, cough, wheeze, and chest tightness. The symptoms can begin early in a work shift, towards the end of a shift, or hours after a shift. They generally, but do not always, improve or remit during periods away from work, such as on weekends or holidays.

Green and roasted coffee dust and castor beans (from cross-contamination of bags used to transport coffee) are known risk factors for occupational asthma [Figley and Rawling 1950; Karr et al. 1978; Zuskin et al. 1979, 1985; Thomas et al. 1991]. Persons who become sensitized (develop an immune reaction) to coffee dust can subsequently react to relatively low concentrations in the air. Others can experience irritant-type symptoms from exposure to coffee dust [Oldenburg et al. 2009].

\section{Process Description}

In April 2019, the coffee roasting, flavoring, and packaging facility employed approximately seven full-time production employees, and one part-time administrative employee. During our visit five employees worked production, and one employee was on travel. The employees were not represented by a union. The facility was located in a single-story building with a production area of approximately 7,000 square feet. An employee breakroom, offices, and a small administrative space were located adjacent to the main production area. The production area included the production office, green bean storage racks, green bean blending, one roaster, two large grinders, roasted bean or off-gassing storage racks, flavoring area, and packaging area. The coffee facility produced ground and whole bean coffee, flavored and unflavored coffee for wholesale and retail. All coffee production was performed by customer order. An average of 500,000 pounds of coffee was roasted and packaged per year.

The coffee processing facility received green coffee bean deliveries once per week in burlap bags shrink-wrapped on wooden pallets. Pallets were moved by forklifts onto shelves in the green bean storage area until ready for roasting. Any blends of coffee bean were performed at the green bean blending station. Blending was performed manually prior to roasting. Blended green beans were moved by forklift to roasting.

The roaster was turned on to begin heating to the desired roasting temperature between $400^{\circ} \mathrm{F}$ and $440^{\circ} \mathrm{F}$. To prepare a batch of coffee beans for roasting, the roaster operator emptied pre-weighed green coffee beans into an automated vacuum that transported the green beans into the roaster hopper. The coffee beans were heated to the desired time, temperature, and color for the roast. The time and temperature varied between different types of roasts. Once the beans were roasted for the desired amount of time, the roaster operator emptied the beans into the cooling bin where they were agitated with a rotating arm. The cooling bin 
had a downdraft exhaust system that drew air over the roasted beans to accelerate cooling. The downdraft system and roaster exhausted to the outside, and an afterburner was installed outside. After the beans were cooled, they were vacuumed through a de-stoner and placed into a large sack to be moved by forklift to either the roasted bean storage/off-gassing area or the grinding area. Whole bean and ground roasted coffee were off-gassed for two days before packaging.

If roasted coffee beans were being ground, the de-stoned sack of roasted coffee was moved by forklift to the top of the grinder. The roasted beans were continuously fed through the grinders into either a 50-gallon trash can or another large sack. Grinding orders ranged from 40 pounds to 600 pounds.

Approximately 22 pounds of ground coffee were scooped at one time into the flavoring hopper. The total amount of coffee flavored and the flavoring used depended on the customer order. Flavorings that were available at the facility included Jamaican' Me Crazy, Hazelnut, Holiday Traditions, French Vanilla, Highlander Grogg, Pumpkin Spice, Irish Cream, Southern Pecan, Caramel, and Cinnamon Sticky Bun. Flavoring was poured into a 5-pound garden sprayer and sprayed over the ground coffee while rotating the hopper for approximately 10 minutes. After the coffee was flavored, it was poured from the hopper into a 50-gallon garbage can or 18-gallon storage tote prior to being sent to packaging.

There were two packaging lines operating at the time of our survey, whole bean and ground coffee. Whole bean coffee was packaged into 1- or 5-pound bags using an automated packaging system. Ground coffee was packaged into 1- to 8-ounce bags using an automated packaging system.

Accumulated chaff in the roaster was cleaned from the roaster using a vacuum. At the end of the day, the floors were swept using a push broom.

\section{Methods}

We conducted our visit to the facility during April 2019. We held an opening meeting with management and employees, collected air samples, and performed a ventilation assessment. At the conclusion of our site visit, we held a closing meeting with management and employees.

We had the following objectives for the health hazard evaluation:

1. Measure employees' exposure to diacetyl, 2,3-pentanedione, and 2,3-hexanedione during coffee processing;

2. Identify process areas or work tasks associated with emissions of diacetyl, 2,3-pentanedione, and 2,3-hexanedione;

3. Measure levels of $\mathrm{CO}$ and $\mathrm{CO}_{2}$ throughout the facility; 


\section{Industrial Hygiene Survey}

\section{Sampling Times for Alpha-Diketones}

We designed the sampling strategy to assess full-shift exposures and identify tasks and processes that were the greatest contributors to worker exposure to alphadiketones. Sampling was conducted over two days. For diacetyl, 2,3-pentanedione, and 2,3-hexanedione, air samples were collected over seconds, minutes, and hours. Samples collected over minutes can help inform recommendations related to STELs, and those collected over hours can help determine average concentrations that can be compared with the NIOSH RELs for diacetyl and 2,3-pentanedione. These average concentrations might not tell us about short-term peak exposures that could be relevant to respiratory health, particularly when tasks are repeated multiple times per day. Therefore, during particular tasks, we collected personal air samples over several minutes; these samples can provide information about which tasks have relatively higher exposures. To help identify point sources of chemicals, we also performed real-time sampling and collected instantaneous samples over seconds.

Employees who participated in air sampling were given the opportunity to request their individual air sampling results.

Air Sampling and Analysis Using Modified Occupational Safety and Health Administration (OSHA) Methods 1013/1016

We collected personal and area air samples for diacetyl, 2,3-pentanedione, and 2,3-hexanedione on silica gel sorbent tubes on two days during the industrial hygiene survey. The samples were collected and analyzed according to the modified OSHA sampling and analytical Methods 1013/1016 [OSHA 2008; OSHA 2010; LeBouf and Simmons 2017]. In accordance with the two methods, two glass silica gel sorbent tubes were connected by a piece of tubing and inserted into a protective, light-blocking cover. The tubes were connected in series to a sampling pump pulling air through the tubes at a flow rate of 50 milliliters per minute ( $\mathrm{mL} / \mathrm{min})$. The sampling setup was attached to an employee's breathing zone or placed in an area basket in various places throughout the facility. For full-shift sampling, we collected two consecutive 3-hour samples and calculated the TWA concentration from the two samples, assuming that the total 6-hour monitoring results reflected a full work shift (8hour) TWA exposure. Although this can introduce some error, it is a conservative approach that is more protective of employees than the alternative assumption of no exposure during the last two hours of the shift. We refer to these samples as "full-shift samples" throughout this report. We also collected personal short-term task-based samples in the same manner, but the sampling pump flow rate was $200 \mathrm{~mL} / \mathrm{min}$ as detailed in OSHA Methods 1013 and 1016 [OSHA 2008; 2010]. Sampling times were dependent on the duration of the task being performed.

Analyses of the samples were performed in the NIOSH Respiratory Health Division's Organics Laboratory. The samples were extracted for one hour in 95\% ethanol:5\% water containing 3-pentanone as an internal standard. Samples were analyzed using an Agilent 7890/7001 gas chromatograph/mass spectrometer system operated in selected ion monitoring mode for increased sensitivity compared with the traditional flame ionization detector used in 
OSHA Methods 1013 and 1016 [LeBouf and Simmons 2017].

A limit of detection (LOD) is the lowest mass an instrument can detect above background and is a criterion used to determine whether to report a result from a sample. The LODs were $0.01 \mathrm{micrograms}$ per sample ( $\mu \mathrm{g} /$ sample) for diacetyl, $0.014 \mu \mathrm{g} / \mathrm{sample}$ for 2,3-pentanedione, and $0.02 \mu \mathrm{g} / \mathrm{sample}$ for 2,3 -hexanedione. These equate to $0.32 \mathrm{ppb}$ for diacetyl, $0.38 \mathrm{ppb}$ for 2,3-pentanedione, and $0.48 \mathrm{ppb}$ for 2,3-hexanedione for a typical full-shift air sample but varies depending on the volume of air collected during the sampling period. The LODs for task samples are generally higher than typical LOD values for full-shift samples since the air volumes collected during task samples are lower.

\section{Air Sampling and Analysis Using Evacuated Canisters}

We collected instantaneous source air samples for VOCs including diacetyl, 2,3-pentanedione, and 2,3-hexanedione using evacuated canisters. The evacuated canister sampling setup consisted of a 450-mL evacuated canister equipped with an instantaneous flow controller designed for a short sampling duration (less than 30 seconds). For source air samples, a NIOSH employee placed the inlet of the flow control directly at the source of interest.

The canister air samples were analyzed using a pre-concentrator/gas chromatograph/mass spectrometer system [NIOSH 2018b], with the addition of acetaldehyde, acetonitrile, and styrene to the list of quantified compounds. The LODs were $1.2 \mathrm{ppb}$ for diacetyl, $1.2 \mathrm{ppb}$ for 2,3-pentanedione, and $1.8 \mathrm{ppb}$ for 2,3-hexanedione based on a three-times dilution factor. However, LODs are dependent on the pressure inside each canister after the samples have been collected, and they can be higher or lower than typical LOD values.

\section{Bulk Sampling and Headspace Analysis}

We used 50-mL sterile polypropylene centrifuge tubes to collect approximately $40-\mathrm{mL}$ bulk samples of roasted ground coffee and liquid flavoring. For headspace analysis of alphadiketones, we transferred approximately 1 gram of material into a sealed $40-\mathrm{mL}$ amber volatile organic analysis vial and let it rest for 24 hours at room temperature $\left(70^{\circ} \mathrm{F}\right)$ in the laboratory. Then $2 \mathrm{~mL}$ of headspace air was transferred to a $450-\mathrm{mL}$ canister and pressurized to approximately 1.5 times atmospheric pressure. Using the canister analysis system, the concentrations were calculated in ppb of compounds in the headspace as an indicator of emission potential.

\section{Real-time Air Sampling}

We used Tiger VOC detector monitors (10.6 eV photoionization lamp, ION Science, Stafford, TX) to measure concentrations of total VOCs in the air. This sampling was conducted to identify areas where coffee could be releasing total VOCs. Areas where higher concentrations of total VOCs are measured help indicate areas where sampling to characterize specific exposures to alpha-diketones might be necessary. We also collected real-time measurements of $\mathrm{CO}_{2}$ and $\mathrm{CO}$ using TSI Incorporated (Shoreview, MN) VelociCalc Model 9555-X MultiFunction Ventilation Meters equipped with Model 982 IAQ probes. We continuously measured employee personal exposures to CO using a Dräger Pac $(7000$ personal single gas detector (Lübeck, Germany). The Dräger Pac ${ }^{\circledR} 7000$ was placed near the breathing zone of 
employees and worn by employees while they performed their work duties.

\section{Statistical Analysis}

Industrial Hygiene Survey

We performed analyses using SAS version 9.4 (SAS Institute, Cary, NC). We created summary statistics by work area location, job title, and task.

\section{Results}

\section{Industrial Hygiene Survey Results}

\section{Personal and Area Full-shift Air Sampling Results} OSHA Methods 1013/1016

We collected 13 personal and 18 area full-shift air samples over two days (Table A1). All full-shift personal samples exceeded the NIOSH RELs of 5 ppb for diacetyl or $9.3 \mathrm{ppb}$ for 2,3-pentanedione. Full-shift personal samples for employees working in the roasting, grinding, and packaging production areas ranged from 106.5 to $185.4 \mathrm{ppb}$ for diacetyl and 108.4 to $279.9 \mathrm{ppb}$ for 2,3-pentanedione. Full-shift personal samples for employees working in administrative areas or spending intermittent time in the production areas ranged from 38.1 to $75.9 \mathrm{ppb}$ for diacetyl and 20.5 to $68.7 \mathrm{ppb}$ for 2,3-pentanedione.

NIOSH RELs are intended to be directly compared to personal measurements; therefore, an area air sample that exceeds a NIOSH REL only indicates the potential for personal exposures. Full-shift area samples exceeded the NIOSH RELs for diacetyl or 2,3-pentanedione. The highest full-shift area air concentrations for diacetyl (238.7 ppb) and 2,3-pentanedione (259.9 ppb) were measured near the main grinder (grinder 1), and in the roasted bean storage area (250.4 ppb diacetyl and $276.8 \mathrm{ppb}$ 2,3-pentanedione).

\section{Task-Based Air Sampling Results}

OSHA Methods 1013/1016

We collected 21 personal task air samples (Table A2). Task duration ranged from seven minutes to 18 minutes. We collected personal task air samples while employees flavored coffee $(n=3)$, ground coffee $(n=6)$, packaged roasted coffee $(n=6)$, and roasted coffee $(n=6)$. The highest task-based TWA exposures to diacetyl (208.4 ppb) and highest task-based TWA exposure to 2,3-pentanedione (1,150 ppb) were measured while an employee used caramel flavoring to flavor medium/light roast ground coffee (Table A2). The second highest taskbased TWA exposure to diacetyl (178.8 ppb) was observed while packaging unflavored whole bean Ethiopian light roast coffee. The second highest task-based TWA exposure to 2,3-pentanedione (245.2 ppb) was observed while an employee packaged unflavored ground medium/dark roast coffee. Elevated levels of diacetyl (164.1 ppb) and 2,3-pentanedione (153.2 ppb) were also measured when employees ground coffee. Air concentrations measured when employees roasted coffee were as high as $171.6 \mathrm{ppb}$ diacetyl and $161.4 \mathrm{ppb}$ 2,3-pentanedione. 


\section{Source Air Sampling Results}

Instantaneous Evacuated Canisters

We collected four source samples for diacetyl and 2,3-pentanedione using evacuated canisters (Table A3). Instantaneous samples were less than 30 seconds in duration. The highest instantaneous source sample for diacetyl (2,463 ppb), 2,3-pentanedione (2,067 ppb), and 2,3-hexanedione ( $96.5 \mathrm{ppb}$ ) were measured at the dispenser of grinder 1 when the grinder was grinding medium roast coffee. An instantaneous sample taken over a large bag of whole bean roasted coffee stored in the off-gassing area measured $259.5 \mathrm{ppb}$ diacetyl, $255.3 \mathrm{ppb}$ 2,3-pentanedione, and $18.1 \mathrm{ppb}$ 2,3-hexanedione. An instantaneous source sample collected at the cooling bin while freshly roasted medium roast coffee was mixed measured $212.0 \mathrm{ppb}$ diacetyl, 177.9 ppb 2,3-pentanedione, and 10.5 ppb 2,3-hexanedione.

\section{Bulk Samples and Headspace Results}

Table A4 presents the bulk sample results using headspace analysis. Air concentrations of diacetyl ranged from $<110 \mathrm{ppb}$ to $535 \mathrm{ppb}$ for ground coffee. Air concentrations of 2,3-pentanedione ranged from $<120 \mathrm{ppb}$ to $671 \mathrm{ppb}$ for ground coffee. Air concentrations of 2,3-hexanedione ranged from $<90 \mathrm{ppb}$ to $303 \mathrm{ppb}$ for ground coffee. The bulk samples for ground coffee were collected from the storage containers in packaging after coffee had off-gassed for at least 24 hours. Liquid flavoring bulk sample air concentrations for diacetyl ranged from $<110 \mathrm{ppb}$ to and 5,811 ppb. Liquid flavoring bulk sample air concentrations for 2,3-pentanedione ranged from $<120 \mathrm{ppb}$ to $253,015 \mathrm{ppb}$. Liquid flavoring bulk sample air concentrations for 2,3-hexanedione ranged from $<90 \mathrm{ppb}$ to $14,972 \mathrm{ppb}$. The bulk samples for liquid flavorings were collected directly from the bulk flavoring containers.

\section{Real-time Monitoring: Carbon Dioxide ( $\left.\mathrm{CO}_{2}\right)$, Carbon Monoxide (CO), and Total Volatile Organic Compounds (VOCs)}

A summary of the real-time $\mathrm{CO}, \mathrm{CO}_{2}$, and total $\mathrm{VOC}$ monitoring results can be seen in Table A5. Levels of $\mathrm{CO}_{2}$ and $\mathrm{CO}$ measured at grinder 1 ranged from $545 \mathrm{ppm}$ to $1,565 \mathrm{ppm}$ for $\mathrm{CO}_{2}$ and $7 \mathrm{ppm}$ to $312 \mathrm{ppm}$ for $\mathrm{CO}$. Total VOC measurements at grinder 1 ranged from $2 \mathrm{ppb}$ to $14,560 \mathrm{ppb}$. Levels of $\mathrm{CO}_{2}$ and $\mathrm{CO}$ measured in the packaging area ranged from $558 \mathrm{ppm}$ to $1,472 \mathrm{ppm}$ for $\mathrm{CO}_{2}$ and $11 \mathrm{ppm}$ to $86 \mathrm{ppm}$ for CO. Total VOC measurements in the packaging area ranged from $1 \mathrm{ppb}$ to $11,730 \mathrm{ppb}$. Levels of $\mathrm{CO}_{2}$ and $\mathrm{CO}$ measured in the off-gassing and staging area ranged from $512 \mathrm{ppm}$ to $1,342 \mathrm{ppm}$ for $\mathrm{CO}_{2}$ and $10 \mathrm{ppm}$ to $65 \mathrm{ppm}$ for $\mathrm{CO}$. Area monitoring of the flavoring area measured levels of $\mathrm{CO}_{2}$ and $\mathrm{CO}$ that ranged from $609 \mathrm{ppm}$ to 1,041 ppm for $\mathrm{CO}_{2}$ and $12 \mathrm{ppm}$ to $47 \mathrm{ppm}$ for CO. Total VOC measurements in the flavoring area ranged from $425 \mathrm{ppb}$ to $4,702 \mathrm{ppb}$.

Table A6 presents a summary of continuous, real-time personal measurements of CO. All (10 of 10) full-shift personal concentrations for carbon monoxide were below the NIOSH recommended exposure limit of $35 \mathrm{ppm}$, but all measurements exceeded the action level of $17.5 \mathrm{ppm}$. A single personal CO measurement (234 ppm) for a grinder operator exceeded the NIOSH ceiling limit of 200 ppm for CO exposure. The NIOSH ceiling limit for CO should not be exceeded at any time. 


\section{Discussion}

Overall, high concentrations from area samples for total VOCs, CO, diacetyl, and 2,3-pentanedione were observed in areas where roasted coffee was ground. Diacetyl, 2,3-pentanedione, 2,3-hexanedione, other VOCs, and other compounds such as $\mathrm{CO}_{2}$ and $\mathrm{CO}$ are naturally produced when coffee beans are roasted, and grinding the roasted coffee beans produces greater surface area for the off-gassing of these chemicals [Anderson et al. 2003; Akiyama et al. 2003; Daglia et al. 2007; Newton 2002; Nishimura et al. 2003; Raffel and Thompson 2013]. In addition, flavorings added to roasted coffee can contain diacetyl or 2,3-pentanedione. Occupational exposure to diacetyl and 2,3-pentanedione can cause loss of lung function and the lung disease obliterative bronchiolitis [NIOSH 2016a]. Some employees developed obliterative bronchiolitis while working at another coffee roasting and packaging facility that used flavorings and had elevated levels of diacetyl and 2,3-pentanedione [CDC 2013; Bailey et al. 2015; Duling et al. 2016]. Exposure to green and roasted coffee dust is a risk factor for work-related asthma [Harvey et al. 2020].

\section{Alpha-Diketones}

Personal Air Sampling

All personal full-shift air samples collected on employees who perform various duties inside the facility using standard OSHA methods were above the limit of detection and the NIOSH REL for diacetyl or 2,3-pentanedione. As noted earlier, the RELs should be used as a guideline to indicate when steps should be taken to reduce exposures in the workplace. The levels we measured in April 2019 were above NIOSH recommendations. As described in the quantitative risk assessment from the NIOSH Criteria Document (Tables 5-27 and 5-29) [NIOSH 2016a], after a 45-year working lifetime exposure to 100 ppb diacetyl (a concentration lower than the highest concentration (185.4 ppb) measured at this facility), NIOSH estimated that 25.7 in 1,000 workers would develop reduced lung function (FEV1 below the lower limit of normal). NIOSH predicted that around 2.7 in 1,000 workers exposed to diacetyl at $100 \mathrm{ppb}$ would develop more severe lung function reduction (FEV1 below 60\% predicted, defined as at least moderately severe by the American Thoracic Society [Pellegrino et al. 2005]). After a 45-year working lifetime exposure to 200 ppb diacetyl (a concentration higher than the highest concentration measured at this facility), NIOSH estimated that 58.7 in 1,000 workers would develop reduced lung function (FEV1 below the lower limit of normal). NIOSH predicted that 6.4 in 1,000 workers exposed to diacetyl at $200 \mathrm{ppb}$ would develop more severe lung function reduction. The effects of a working lifetime exposure at $185.4 \mathrm{ppb}$ diacetyl is closer to $200 \mathrm{ppb}$ than $100 \mathrm{ppb}$. NIOSH recommends keeping diacetyl concentrations below $5 \mathrm{ppb}$ because at this level, the risk of reduced lung function after a working lifetime of exposure is below 1 in 1,000 workers. NIOSH recommends taking steps to reduce diacetyl exposures to below the REL of $5 \mathrm{ppb}$ whenever possible.

\section{Area Air Sampling}

We note that NIOSH RELs are intended to be directly compared with personal measurements; therefore, an area air sample that exceeds a NIOSH REL is only an indication of potential personal exposures. All production areas sampled had full-shift TWA air 
concentrations that were above the limit of detection and the NIOSH REL for diacetyl and 2,3-pentanedione.

\section{Task-Based Exposures}

Coffee processing involves multiple tasks that can cause intermittent exposure to diacetyl and 2,3-pentanedione. Traditional full-shift sampling will not characterize these intermittent, peak exposures. Measured short-term peak exposures contribute to average full-shift exposures and can help identify sources and processes that generate diacetyl and 2,3-pentanedione and that can be targeted with engineering controls.

Tasks with the highest air concentrations of diacetyl or 2,3-pentanedione occurred when employees 1) flavored roasted ground coffee (208.4 ppb diacetyl; 1,150 ppb 2,3-pentanedione), 2) ground unflavored coffee (164.1 ppb diacetyl; $153.2 \mathrm{ppb}$

2,3-pentanedione), and 3) packaged ground coffee (178.8 ppb diacetyl; $245.2 \mathrm{ppb}$ 2,3-pentanedione. All task air samples were above the limit of detection.

\section{Source Air Sampling}

We also measured diacetyl and 2,3-pentanedione using instantaneous sampling, in which sample duration was less than 30 seconds. These instantaneous samples were collected to identify and describe point sources of diacetyl and 2,3-pentanedione. The highest instantaneous levels were measured at the dispenser of the grinder $1(2,463 \mathrm{ppb}$ diacetyl; 2,067 ppb 2,3-pentanedione). The greater surface area for off-gassing produced during grinding could have resulted in the higher air concentrations observed while employees performed grinding tasks [Akiyama et al. 2003]. Concentrations of diacetyl and 2,3-pentanedione in a sample collected at the opening of roasted coffee supersacks measured $259.5 \mathrm{ppb}$ for diacetyl and $255.3 \mathrm{ppb}$ for 2,3-pentanedione.

\section{Bulk Samples}

Diacetyl is not found in green beans and forms later in the coffee roasting process [Daglia et al. 2007]. As expected, we found that roasted ground coffee emits alpha-diketones into the headspace of sealed vessels, indicating that roasted coffee is a considerable source of alphadiketones in the facility. Bulk samples of medium espresso roasted ground coffee resulted in the highest level of diacetyl from headspace analysis, $535 \mathrm{ppb}$. Bulk samples of dark roasted ground coffee resulted in the highest levels of 2,3-hexanedione from headspace analysis, 303 ppb. The amount of time ground coffee had off-gassed could be responsible for difference in headspace analysis results. Bulk samples of liquid caramel flavoring resulted in the highest concentrations of 2,3-hexanedione and 2,3-pentanedione at 14,972 ppb and 253,015 respectively. Bulk samples of liquid hazelnut flavoring resulted in the highest concentrations of diacetyl at 5,811 ppb. Liquid flavoring emits alpha-diketones into the headspace of sealed vessels, indicating that liquid flavorings are a considerable source of alpha-diketones in the facility.

Real-time Sampling for $\mathrm{CO}, \mathrm{CO}_{2}$, and VOCs

Our real-time monitoring found that the highest overall levels of $\mathrm{CO}$ for area samples were observed at the grinders and in packaging. The area sample for grinder 1 had the highest 
maximum CO measurement of $312 \mathrm{ppm}$. Area average CO levels ranged from $26.1 \mathrm{ppm}$ to $43.3 \mathrm{ppm}$ throughout the facility. While OELs are specified for personal air samples, we indirectly compare area air samples with OELs to give a hazard context to the measured air concentration as an indicator of the potential for worker exposure. Personal $\mathrm{CO}$ exposures were measured in the low to high $20 \mathrm{ppm}$ range. Personal CO levels were lower or comparable to average area CO levels (26.1 to $43.3 \mathrm{ppm}$ ) indicating a well-mixed atmosphere in the facility. One personal CO measurement exceeded the NIOSH ceiling limit of 200 ppm for $\mathrm{CO}$ exposure, $234 \mathrm{ppm}$. The NIOSH ceiling limit for $\mathrm{CO}$ should not be exceeded at any time. All $\mathrm{CO}_{2}$ measurements were below the NIOSH REL (5,000 ppm) and OSHA PEL $(5,000 \mathrm{ppm})$.

\section{Respiratory Protection}

Until engineering and administrative controls are in place, we recommend respiratory protection to reduce exposures to alpha-diketones. The choice of respirator should be guided by personal exposure sampling for diacetyl and 2,3-pentanedione. Information on respirators can be found in Chapter 8 of the NIOSH Criteria Document [NIOSH 2016a] and in the NIOSH Respirator Selection Logic [NIOSH 2004]. The selection of a specific respirator depends on the particular situation and should be made only by qualified personnel [NIOSH 2016a].

\section{Ventilation}

Generally, the production area would be expected to have the highest concentrations of airborne contaminants. To keep these contaminants confined to the production area and prevent them from spreading into adjacent areas, the production area should be maintained under negative pressure relative to the adjacent spaces. This would ensure air from the adjacent spaces flows into the production area and not vice versa. At the time of sampling, the production area was open to administrative areas and offices and general exhaust ventilation was not present. Two exhaust fans were present on the east and west walls of the facility. The exhaust fan above the flavoring area was turned on during flavoring activity.

\section{Local exhaust ventilation}

Local exhaust ventilation systems can capture contaminants when generated and remove contaminants before inhalation by employees can occur. Local exhaust ventilation systems generally consist of hoods or enclosures, duct work, or fans. Depending on the contaminant and whether air is recirculated, filters or other air cleaning technologies can also be incorporated. After properly designed local exhaust ventilation systems are installed, overall workplace exposure levels can be reduced by removing contaminants at the source. The grinders and flavoring area could be modified with local exhaust ventilation that would help reduce overall alpha-diketone concentrations in the facility.

\section{Conclusions}

Work tasks or job duties performed during our visit resulted in air concentrations of diacetyl and 2,3-pentanedione that exceeded the NIOSH RELs for diacetyl and 2,3-pentanedione. 
The highest full-shift diacetyl and 2,3-pentanedione exposure measurements were observed on employees that ground coffee or packaged ground coffee. We observed the highest instantaneous air concentrations of diacetyl and 2,3-pentanedione during grinding tasks. We observed the highest task-based TWA exposures to diacetyl and 2,3-pentanedione while an employee flavored ground coffee. Personal full-shift $\mathrm{CO}$ exposures exceeded the action level of $17.5 \mathrm{ppm}$ necessitating the need for intervention such as ventilation to control exposure to $\mathrm{CO}$ and other process emissions.

During our visit, there were two exhaust fans on the east and west walls of the facility. The exhaust fan on the east wall was turned on only during flavoring. The exhaust fan on the west wall was not turned on during our visit. There was no additional general exhaust ventilation at the facility. Air sampling results could be impacted day-to-day by variations in the weather, doors or windows being opened or closed, or operating states (on vs. off) of the exhaust fans. During flavoring tasks, flavorings were sprayed onto ground coffee using a small tank sprayer. Minimizing spraying of flavorings could help reduce overall alpha-diketone levels in the facility.

A new production facility is currently under construction. The new facility has made changes to production design, such as storing roasted coffee in silos, improving general exhaust ventilation, and making considerations for local exhaust ventilation. The recommendations below are based on exposures measured during our survey in April 2019. However, these recommendations could help reduce overall alpha-diketone and carbon monoxide levels in the new facility.

\section{Recommendations}

On the basis of our findings, we recommend the actions listed below. We encourage this coffee roasting, flavoring, and packaging facility to use a labor-management health and safety committee or working group to discuss our recommendations and develop an action plan. Our recommendations are based on an approach known as the hierarchy of controls. This approach groups actions by their likely effectiveness in reducing or removing hazards. In most cases, the preferred approach is to eliminate hazardous materials or processes and install engineering controls to reduce exposure or shield employees.

\section{Engineering Controls}

Engineering controls reduce employees' exposures by removing the hazard from the process or by placing a barrier between the hazard and the employee. Engineering controls protect employees effectively without placing primary responsibility of implementation on the employee.

1. Ensure the exhaust fan in the flavoring area is always turned on whenever flavoring tasks are performed. Once in the new facility, consult with a ventilation engineer to install local exhaust ventilation at the flavoring area to reduce air concentrations of alphadiketones (diacetyl and 2,3-pentainedione). 
2. Keep all doors between the production space and non-production space closed at all times.

3. Consult with a ventilation engineer to install local exhaust ventilation at the grinders to reduce air concentrations of alpha-diketones (diacetyl and 2,3-pentanedione), and carbon monoxide during grinding of coffee. Relocating the grinders to an exterior wall might make implementation of engineering controls easier.

\section{Administrative Controls}

Administrative controls are employer-dictated work practices and policies implemented to reduce or prevent hazardous exposures. Their effectiveness depends on employer commitment and employee acceptance. Regular monitoring and reinforcement are necessary to ensure that policies and procedures are followed consistently.

1. Whenever possible, employees should avoid spending time in the immediate area where coffee is being ground or ground coffee is being packaged.

2. Whenever possible, store roasted whole beans and ground coffee in storage containers with lids or silos to aid in reducing the overall emission of alpha-diketones and other chemicals including $\mathrm{CO}$ and $\mathrm{CO}_{2}$, into the workplace. Specifically, ensure that whenever possible, containers filled with ground coffee are kept covered.

3. Whenever possible, eliminate spray application of flavorings to ground coffee to aid in reducing the overall emission of alpha-diketones. When liquid flavorings are sprayed, small droplets are created that can be inhaled into the airways.

4. To reduce exposures to VOCs (including alpha-diketones) and $\mathrm{CO}$, minimize production tasks that require employees to place their heads directly above or inside the roasted bean bins.

5. Continue to periodically clean the roaster's exhaust according to manufacturer instructions, including removing chaff build-up to reduce a fire hazard and improve the efficiency, energy usage, and roaster performance.

6. Ensure employees understand potential hazards (e.g., diacetyl, 2,3-pentanedione, $\mathrm{CO}, \mathrm{CO}_{2}$, dust) in the workplace and how to protect themselves. OSHA's Hazard Communication Standard, also known as the "Right to Know Law" [29 CFR 1910.1200] requires that employees are informed and trained on potential work hazards and associated safe practices, procedures, and protective measures.

7. Ensure employees are educated to consider the risks of further exposure if they develop lower respiratory symptoms (e.g., cough, shortness of breath, wheezing) that are progressive and severe in degree. Employees should report new, persistent, or worsening respiratory symptoms to their personal healthcare providers and to a designated individual at this workplace. Employees with new, persistent, or worsening respiratory symptoms should share this report with their healthcare providers.

\section{Personal Protective Equipment}

The effectiveness of respiratory protection as personal protective equipment depends on avoiding breakdowns in implementation that can cause insufficient protection from 
respiratory exposures. Proper use of respiratory protection (respirators) requires a comprehensive respiratory protection program and a high level of employee and management involvement and commitment to assure the right type of respirator is chosen for each hazard, respirators fit users, respirators are maintained in good working order, and respirators are worn when needed. Supporting programs such as training, change-out schedules, and medical assessment might be necessary. Respirators should not be the sole method for controlling hazardous inhalation exposures. Rather, respirators should be used until effective engineering and administrative controls are in place.

1. Until engineering and administrative controls are in place, respiratory protection for diacetyl and 2,3-pentanedione should be used to reduce exposures to alpha-diketones. The choice of respirator should be guided by personal exposure sampling for diacetyl and 2,3-pentanedione. Respirators have assigned protection factors (APFs). APF refers to the highest level of protection a properly selected respirator can provide. For instance, air-purifying half-face respirators have an APF of 10, and air-purifying fullface respirators have an APF of 50. Powered-air purifying respirators have APFs of 25, 50 , or 1,000 . The OSHA APFs can be found in Table 1 of OSHA Respiratory Protection Standard at https://www.osha.gov/laws-regs/regulations/standardnumber/1910/1910.134

Based on a REL for diacetyl of $5 \mathrm{ppb}$ :

- a properly fit-tested half-face respirator with an APF of 10 and organic vapor cartridges would be protective for a diacetyl concentration up to $50 \mathrm{ppb}$ (10 APF x 5 $\mathrm{ppb}=50 \mathrm{ppb}$ )

- a properly fit-tested half-face respirator with an APF of 50 and organic vapor cartridges would be protective for a diacetyl concentration up to $250 \mathrm{ppb}$ of diacetyl (50 APF x 5 ppb $=250 \mathrm{ppb})$

- a properly fit-tested PAPR with an APF of 1,000 and organic vapor cartridges would be protective for a diacetyl concentrating up to 5,000 ppb of diacetyl (1,000 APF x 5 $\mathrm{ppb}=5,000 \mathrm{ppb})$

Based on a REL for 2,3-pentanedione of $9.3 \mathrm{ppb}$ :

- a properly fit-tested half-face respirator with an APF of 10 and NIOSH-certified organic vapor cartridges would be protective for a 2,3-pentanedione concentration up to $93 \mathrm{ppb}(10 \mathrm{APF} \times 9.3 \mathrm{ppb}=93 \mathrm{ppb})$

- a properly fit-tested half-face respirator with an APF of 50 and NIOSH-certified organic vapor cartridges would be protective for a 2,3-pentanedione concentration up to $465 \mathrm{ppb}$ of 2,3-pentanedione (50 APF x $9.3 \mathrm{ppb}=465 \mathrm{ppb})$

- a properly fit-tested PAPR with an APF of 1,000 and NIOSH-certified organic vapor cartridges would be protective for a 2,3-pentanedione concentration up to 9,300 ppb of 2,3-pentanedione (1,000 APF x $9.3 \mathrm{ppb}=9,300 \mathrm{ppb})$

Note that organic vapor cartridges are not protective for exposures to carbon monoxide. Based on personal exposure sampling for diacetyl and 2,3-pentainedione during our industrial hygiene survey in April 2019, we recommend a properly fit-tested half-face respirator with an APF of 50 and NIOSH-certified organic vapor cartridges until alpha- 
diketone concentrations can be reduced at your facility. If concentrations of alphadiketones have changed since our visit or change in the future, the level of recommended respiratory protection would need to be adjusted following the guidance above.

Information on respirators can be found in Chapter 8 of the NIOSH Criteria Document [NIOSH 2016a] and in the NIOSH Respirator Selection Logic [NIOSH 2004]. The selection of a specific respirator depends on the particular situation and should be made only by qualified personnel [NIOSH 2016a].

2. Implement a written respiratory protection program as required by OSHA Respiratory Protection Standard (29 CFR 1910.134), including medical evaluation, training, fit testing, maintenance, and use requirements for all employees who use respiratory protection.

3. Ensure N95 disposable filtering-face piece respirators available for voluntary use for protection against green or roasted coffee dust exposure such as during emptying burlap bags of green beans into the storage silos, cleaning the roaster exhaust system of chaff, emptying the chaff containers, or cleaning the green bean storage area. N95 respirators should be available in various sizes, and each potential N95 user should receive a copy of Appendix D of the OSHA Respiratory Protection Standard about Appendix D and voluntary use of respirators can be found on the OSHA website at https://www.osha.gov/laws-regs/regulations/standardnumber/1910/1910.134AppD.

Please be aware N95s are not protective against alpha-diketones (diacetyl, 2,3-pentanedione, or 2,3-hexanedione). In cases of dual exposure to dust and alphadiketones, NIOSH-certified organic vapor cartridges (for the alpha-diketones) and particulate cartridges/filters (for the dust) would be warranted.

\section{Medical Monitoring}

The purpose of a medical monitoring program is to help assure the health of employees who have workplace exposures to health hazards (e.g., diacetyl, 2,3-pentanedione, green coffee beans/dust) known to pose risk for potentially serious health conditions or illnesses such as obliterative bronchiolitis or asthma.

1. As detailed in the NIOSH Criteria Document [NIOSH 2016a], a medical monitoring program is recommended for all employees who work in the production areas or enter production areas for a total of 40 hours or more per year. According to the NIOSH Criteria Document, employees should have baseline medical evaluations before they are allowed to work in or enter areas where they might be exposed to diacetyl, 2,3-pentanedione, or similar flavoring compounds. The NIOSH Criteria Document recommends employees in the medical monitoring program be evaluated with a questionnaire (to obtain health and work task information) and spirometry (to assess lung function) every six months. 
2. If an employee is identified as likely having lung disease from exposure to diacetyl, 2,3-pentanedione, or a similar flavoring compound, it should be viewed as a sentinel event indicating that there was a breakdown in exposure controls, and there is potential risk for co-workers. Should this occur, the source of exposure should be identified and brought under control. In addition, increased intensity of medical monitoring would be required for all employees performing similar job tasks or having similar or greater potential for exposure. The NIOSH Criteria Document provides detailed guidance on responses to such sentinel events [NIOSH 2016a].

\section{Smoking Cessation Program}

In a workplace with risk of occupational lung disease, prevention of smoking-related lung disease is important and makes the detection of work-related adverse effects easier. If employees smoke, we recommend implementing a smoking cessation program to assist employees to stop smoking. The Centers for Disease Control and Prevention offers tools and resources for setting up a smoking cessation program [CDC 2019]. 


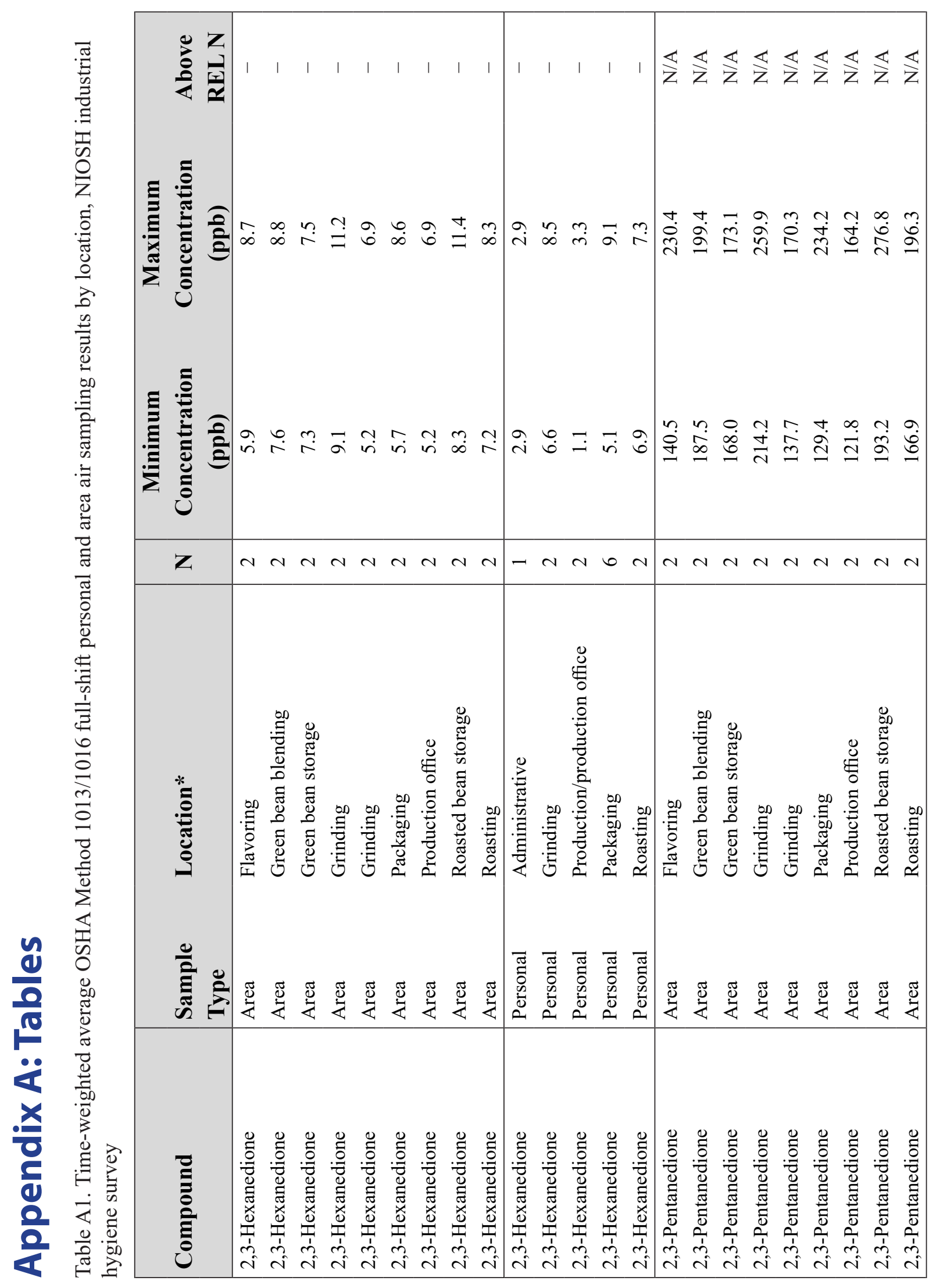




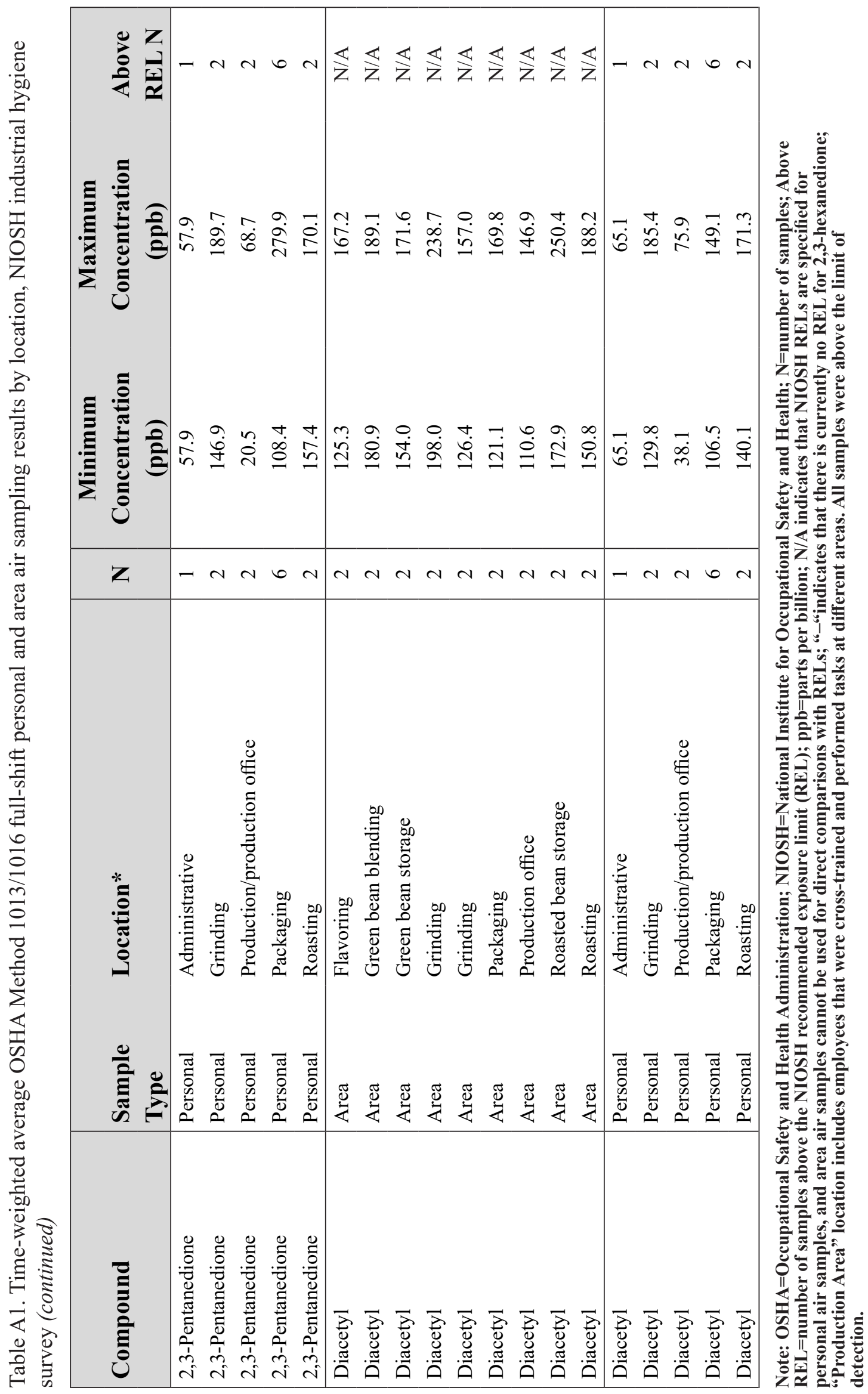




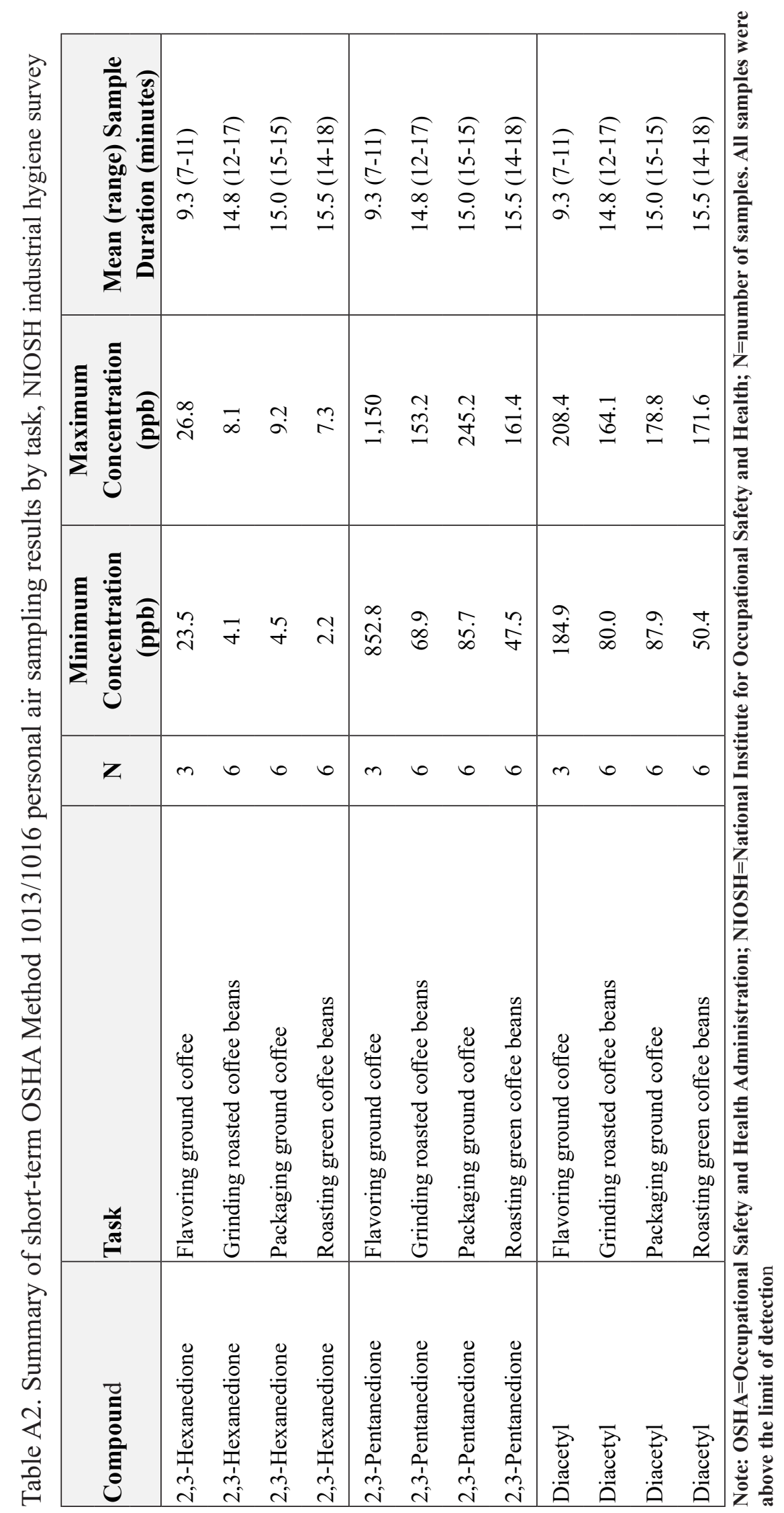




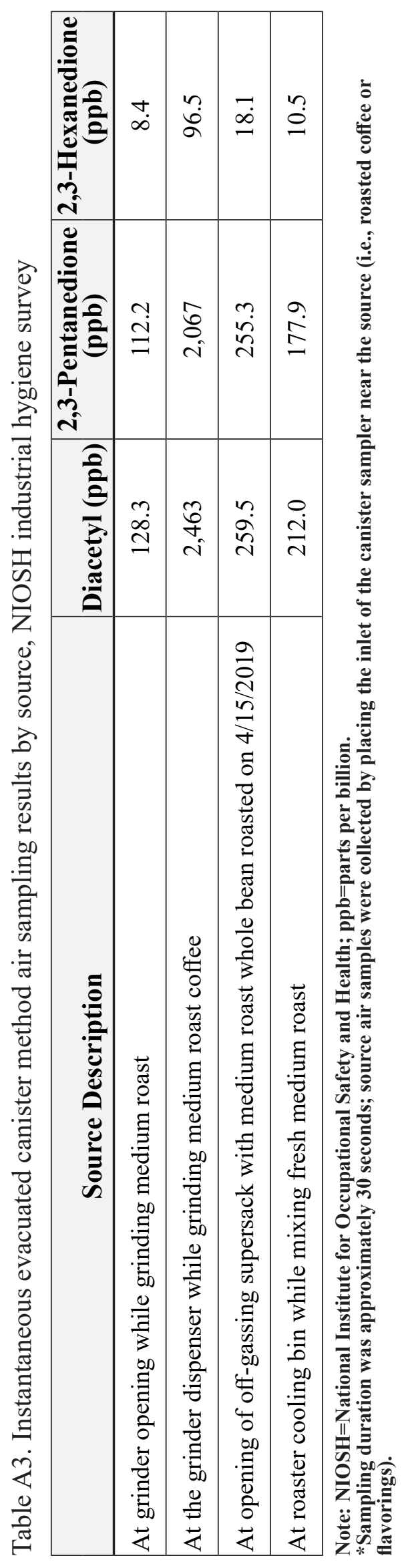

Health Hazard Evaluation Report 2018-0134-3373 


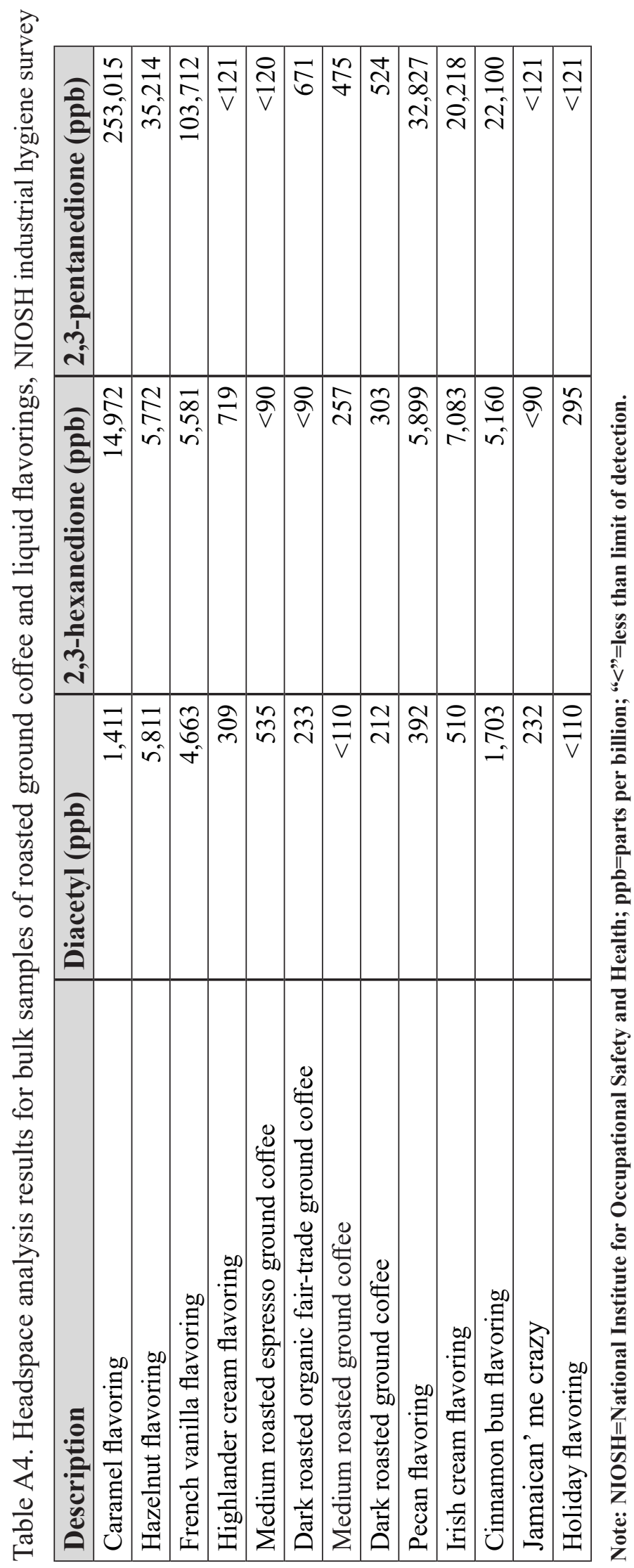




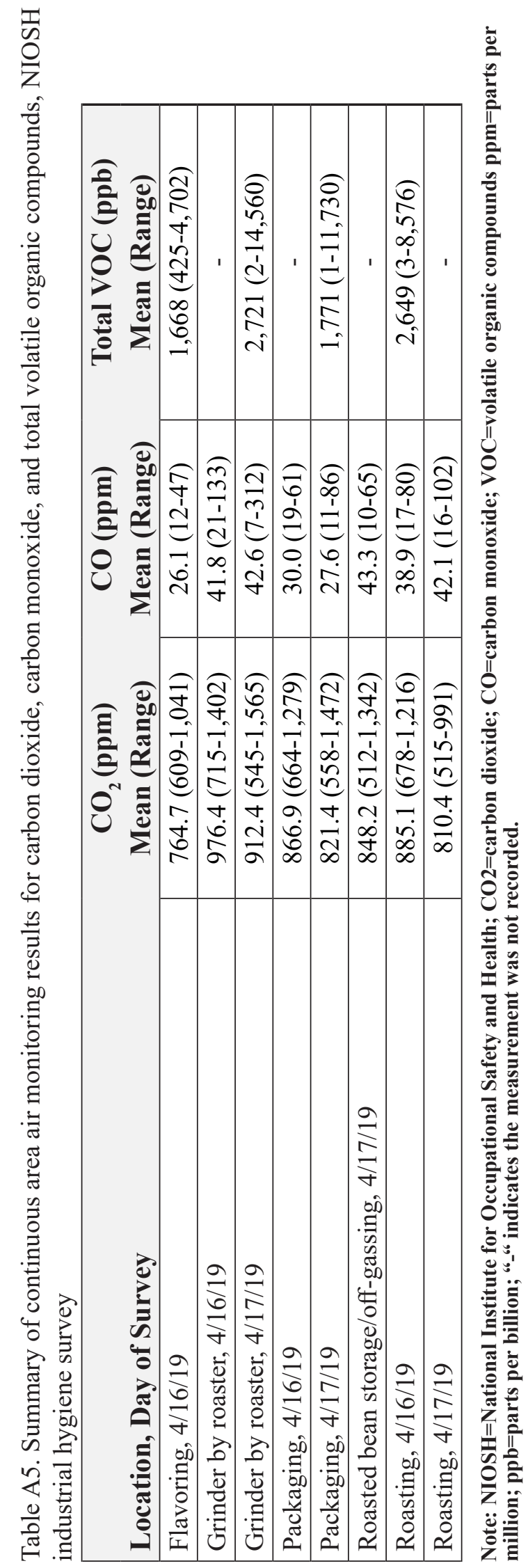




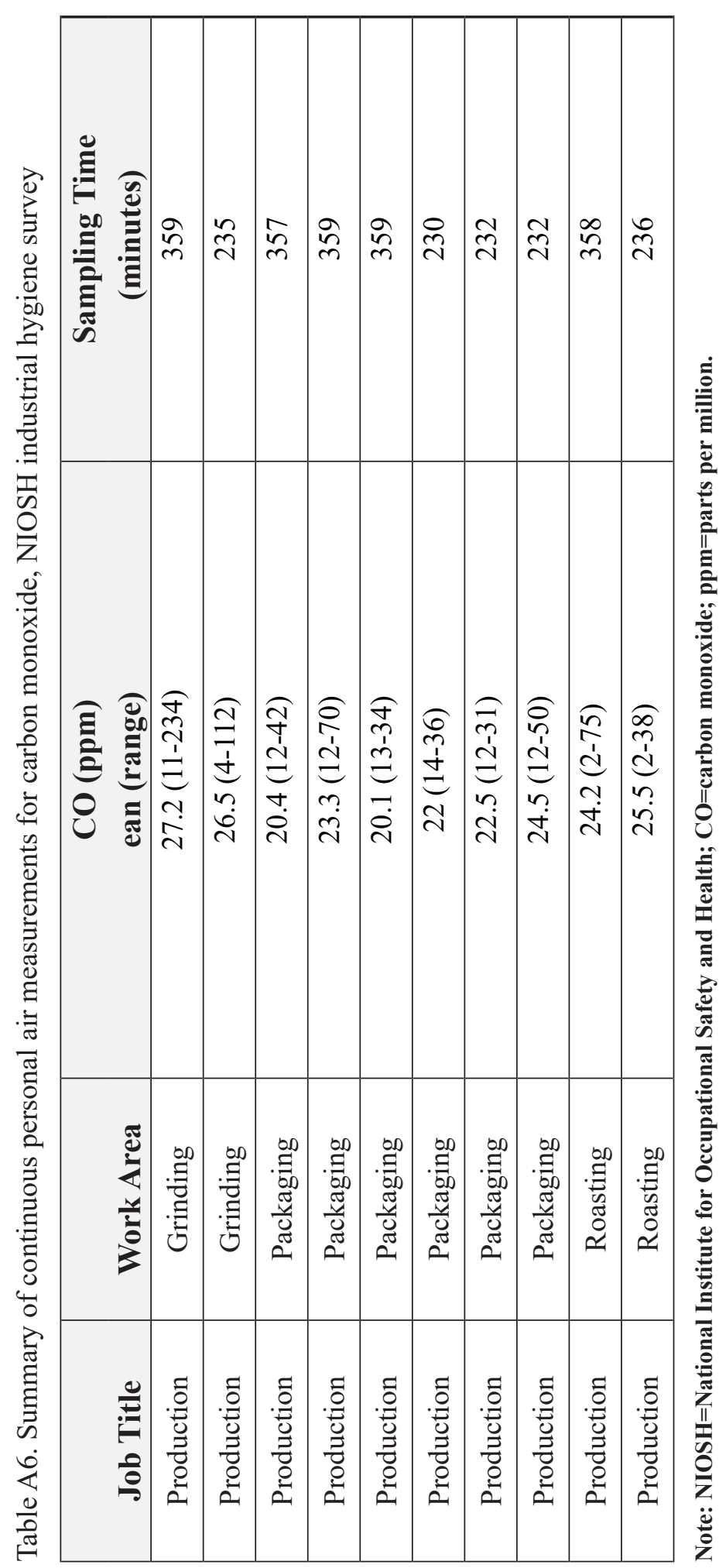




\section{References}

ACGIH [2019]. 2019 TLVs ${ }^{\circledR}$ and BEIs ${ }^{\circledR}$ : Threshold limit values for chemical substances and physical agents and biological exposure indices. Cincinnati, $\mathrm{OH}$ : American Conference of Governmental Industrial Hygienists.

Akiyama M, Murakami K, Ohtani N, Iwatsuki K, Sotoyama K, Wada A, Tokuno K, Iwabuchi H, Tanaka K [2003]. Analysis of volatile compounds released during the grinding of roasted coffee beans using solid-phase microextraction. J Agric Food Chem 51(7):1961-1969, https:// doi.org/10.1021/jf020724p.

Anderson BA, Shimoni E, Liardon R, Labuza P [2003]. The diffusion kinetics of carbon dioxide in fresh roasted and ground coffee. J Food Eng 59(1):71-78, https://doi.org/10.1016/ $\underline{\mathrm{S} 0260-8774(02) 00432-6 .}$

Bailey RL, Cox-Ganser JM, Duling MG, LeBouf RF, Martin SB Jr, Bledsoe TA, Green BJ, Kreiss K [2015]. Respiratory morbidity in a coffee processing workplace with sentinel obliterative bronchiolitis cases. Am J Ind Med 58(12):1235-1245, https://doi.org/10.1002/ ajim.22533.

CDC [2013]. Obliterative bronchiolitis in workers in a coffee-processing facility-Texas, 2008-2012. MMWR 62(16):305-307, https://www.cdc.gov/mmwr/preview/mmwrhtml/ mm6216a3.htm.

CDC [2018]. Carbon monoxide. Cincinnati, OH: U.S. Department of Health and Human Services, Centers for Disease Control and Prevention, National Institute for Occupational Safety and Health, https://www.cdc.gov/niosh/topics/co-comp/default.html.

CDC [2019]. Smoking \& tobacco use: quit smoking, https://www.cdc.gov/tobacco/quit smoking/index.htm.

CFR. Code of Federal Regulations. Washington, DC: U.S. Government Printing Office, Office of the Federal Register.

Chetambath R, Shivashankaran S, Kumar J, Ravindran D, Khalam AA [2020]. Bronchiolitis obliterans in a coffee processing unit worker from Wayanad: report of a rare case. EC Pulmonary and Respiratory Medicine 9(3):01-04, https://www.ecronicon.com/ecprm/pdf/ ECPRM-09-00554.pdf.

Daglia M, Papetti A, Aceti C, Sordelli B, Spini V, Gazzani G [2007]. Isolation and determination of $\alpha$-dicarbonyl compounds by RP-HPLC-DAD in green and roasted coffee. $J$ Agric Food Chem 55(22):8877-8882, https://doi.org/10.1021/jf0719171.

Day G, LeBouf R, Grote A, Pendergrass S, Cummings K, Kreiss K, and Kullman G [2011]. 
Identification and measurement of diacetyl substitutes in dry bakery mix production. J Occup Environ Hyg 8(2):93-103, https://doi.org/10.1080/15459624.2011.547148.

Duling MG, LeBouf RF, Cox-Ganser JM, Kreiss K, Martin SB Jr, Bailey RL [2016]. Environmental characterization of a coffee processing workplace with obliterative bronchiolitis in former workers. J Occup Environ Hyg 13(10):770-781, https://doi.org/10.108 $\underline{0 / 15459624.2016 .1177649 .}$.

Figley KD, Rawling FF [1950] Castor bean: an industrial hazard as a contaminant of green coffee dust and used burlap bags. J Allergy 21(6):545-553, https://doi.org/10.1016/0021$\underline{8707(50) 90106-7 .}$

Harvey RR, Fechter-Leggett ED, Bailey RL, Edwards NT, Fedan, KB, Virji MA, Nett RJ, Cox-Ganser JM, Cummings KJ [2020]. The burden of respiratory abnormalities among workers at coffee roasting and packaging facilities, Front Public Health 8:5, https://doi. org/10.3389/fpubh.2020.00005.

Hawley B, Cox-Ganser JM, Cummings KJ [2017]. Carbon monoxide exposure in workplaces, including coffee processing facilities. Am J Respir Crit Care Med 196(8):10801081, https://doi.org/10.1164/rccm.201703-0513LE.

Henneberger PK, Redlich CA, Callahan DB, Harber P, Lemière C, Martin J, Tarlo SM, Vandenplas O, Torén K; ATS Ad Hoc Committee on Work-Exacerbated Asthma [2011]. An official American Thoracic Society statement: work-exacerbated asthma. Am J Respir Crit Care Med 184(3):368-378, https://doi.org/10.1164/rccm.812011ST.

Hubbs AF, Cumpston AM, Goldsmith WT, Battelli LA, Kashon ML, Jackson MC, Frazer DG, Fedan JS, Goravanahally MP, Castranova V, Kreiss K, Willard PA, Friend S, SchweglerBerry D, Fluharty KL, Sriram K [2012]. Respiratory and olfactory cytotoxicity of inhaled 2,3-pentanedione in Sprague-Dawley rats. Am J Pathol 181(3):829-844, https://doi. org/10.1016/j.ajpath.2012.05.021.

Kanwal R, Kullman G, Piacitelli C, Boylstein R, Sahakian N, Martin S, Fedan K, Kreiss K [2006]. Evaluation of flavorings-related lung disease risk at six microwave popcorn plants. J Occup Environ Med 48(2):149-157, https://doi.org/10.1097/01.jom.0000194152.48728.fb.

Karr RM, Davies RJ, Butcher BT, Lehrer SB, Wilson MR, Dharmarajan V, Salvaggio JE [1978]. Occupational asthma. J Allergy Clin Immunol 61(1):54-65, https://doi. org/10.1016/0091-6749(78)90474-8.

Kim TJ, Materna BL, Prudhomme JC, Fedan KB, Enright PL, Sahakian NM, Windham GC, Kreiss K [2010]. Industry-wide medical surveillance of California flavor manufacturing workers: Cross-sectional results. Am J Ind Med 53(9):857-865, https://doi.org/10.1002/ ajim.20858. 
Kreiss K [2013]. Occupational causes of constrictive bronchiolitis. Curr Opin Allergy Clin Immunol 13(2):167-172, http://doi.org/10.1097/ACI.0b013e32835e0282.

Langford NJ [2005]. Carbon dioxide poisoning. Toxicol Rev 24(4):229-235, https://doi. org/10.2165/00139709-200524040-00003.

LeBouf R, Simmons M [2017]. Increased sensitivity of OSHA method analysis of diacetyl and 2,3-pentanedione in air. J Occup Environ Hyg 14(5):343-348, https://doi.org/10.1080/15 $\underline{459624.2016 .1252846 .}$

LeBouf RF, Aldridge M [2018]. Carbon monoxide emission rates from roasted whole bean and ground coffee. J Air Waste Manag Assoc 69(1):89-96, https://doi.org/10.1080/10962247. 2018.1515125.

LeBouf RF, Hawley B, Cummings KJ [2019]. Potential hazards not communicated in safety data sheets of flavoring formulations, including diacetyl and 2,3-pentanedione. Ann Work Expo Health 63(1):124-130, https://doi.org/10.1093/annweh/wxy093.

Morgan DL, Jokinen MP, Price HC, Gwinn WM, Palmer SM, Flake GP [2012]. Bronchial and bronchiolar fibrosis in rats exposed to 2,3-pentanedione vapors: implications for bronchiolitis obliterans in humans. Toxicol Pathol 40(3):448-465, https://doi. org $/ 10.1177 / 0192623311431946$.

Morgan DL, Jokinen MP, Johnson CL, Price HC, Gwinn WM, Bousquet RW, Flake GP [2016]. Chemical reactivity and respiratory toxicity of the $\alpha$-diketone flavoring agents: 2,3-butanedione, 2,3-pentanedione, and 2,3-hexanedione. Toxicol Pathol 44(5):763-783, https://doi.org/10.1177/0192623316638962.

Newton J [2002]. Carbon monoxide exposure from coffee roasting. Appl Occup Environ Hyg 17(9):600-602, https://doi.org/10.1080/10473220290095899.

National Institute for Occupational Safety and Health (NIOSH) [2004]. NIOSH respirator selection logic. Cincinnati, OH: U.S. Department of Health and Human Services, Centers for Disease Control and Prevention, National Institute for Occupational Safety and Health, DHHS (NIOSH) Publication No. 2005-100, https://www.cdc.gov/niosh/docs/2005-100/ pdfs/2005-100.pdf.

NIOSH [2012]. Flavoring-related lung disease: Information for Healthcare Providers. Cincinnati, OH: U.S. Department of Health and Human Services, Centers for Disease Control and Prevention, National Institute for Occupational Safety and Health, DHHS (NIOSH) Publication 2012-148, http://www.cdc.gov/niosh/docs/2012-148/.

NIOSH [2016a]. Criteria for a recommended standard: occupational exposure to diacetyl and 2,3-pentanedione. By McKernan LT, Niemeier RT, Kreiss K, Hubbs A, Park R, Dankovic D, Dunn KH, Parker J, Fedan K, Streicher R, Fedan J, Garcia A, Whittaker C, Gilbert S, 
Nourian F, Galloway E, Smith R, Lentz TJ, Hirst D, Topmiller J, Curwin B. Cincinnati, OH: U.S. Department of Health and Human Services, Centers for Disease Control and Prevention, National Institute for Occupational Safety and Health, DHHS (NIOSH) Publication No. 2016-111, https://www.cdc.gov/niosh/docs/2016-111/.

NIOSH [2016b]. NIOSH pocket guide to chemical hazards, http://www.cdc.gov/niosh/npg/.

NIOSH [2017]. Work-related asthma, Cincinnati, OH: U.S. Department of Health and Human Services, Centers for Disease Control and Prevention, National Institute for Occupational Safety and Health, https://www.cdc.gov/niosh/topics/asthma/default.html.

Nishimura F, Abe S, Fukunaga T [2003]. Carbon monoxide poisoning from industrial coffee extraction. JAMA 290(3):334, https://jamanetwork.com/journals/jama/articleabstract/196935.

Oldenburg M, Bittner C, Baur X [2009]. Health risks due to coffee dust. Chest 136(2):536544, https://doi.org/10.1378/chest.08-1965.

OSHA (Occupational Safety and Health Administration) [1993]. Compliance and enforcement activities affected by the PELs decision. Washington, DC: U.S. Department of Labor, Occupational Safety and Health Administration, https://www.osha.gov/laws-regs/ standardinterpretations/1993-08-05.

OSHA [2003]. Enforcement policy for respiratory hazards not covered by OSHA permissible exposure limits. Washington, DC: U.S. Department of Labor, Occupational Safety and Health Administration, https://www.osha.gov/laws-regs/standardinterpretations/2018-11-02.

OSHA [2008]. Sampling and analytical methods: Method 1013 -Acetoin and diacetyl. Washington, DC: U.S. Department of Labor, Occupational Safety and Health Administration, https://www.osha.gov/dts/sltc/methods/validated/1013/1013.html.

OSHA [2010]. Sampling and analytical methods: Method 1016 - 2,3-pentanedione. Washington, DC: U.S. Department of Labor, Occupational Safety and Health Administration, https://www.osha.gov/dts/sltc/methods/validated/1016/1016.html.

OSHA [2014]. OSHA fact sheet: Do you have work-related asthma? A guide for you and your doctor. Washington, D.C.: U.S. Department of Labor, Occupational Safety and Health Administration, https://www.osha.gov/Publications/OSHA3707.pdf.

OSHA [2019]. Permissible exposure limits - annotated tables. Washington, D.C.: U.S. Department of Labor, Occupational Safety and Health Administration, https://www.osha.gov/ dsg/annotated-pels/index.html.

Pellegrino R, Viegi G, Brusasco V, Crapo RO, Burgos F, Casaburi R, Coates A, van der Grinten CP, Gustafsson P, Hankinson J, Jensen R, Johnson DC, MacIntyre N, McKay R, 
Miller MR, Navajas D, Pedersen OF, Wanger J [2005]. Interpretative strategies for lung function tests. Eur Respir J 26(5):948-968, https://doi.org/10.1183/09031936.05.00035205.

Raffel JB, Thompson J [2013]. Carbon monoxide from domestic coffee roasting: a case report. Ann Intern Med 159(11):795-796, https://doi.org/10.7326/0003-4819-159-11201312030-00023.

Rose JJ, Wang L, Xu Q, McTiernan CF, Shiva S, Tejero J, Gladwin MT [2017]. Carbon monoxide poisoning: pathogenesis, management, and future directions of therapy. Am J Respir Crit Care Med 195(5):596-606, https://doi.org/10.1164/rccm.201606-1275CI.

Tarlo SM, Lemiere C [2014]. Occupational asthma. N Engl J Med 370:640-649, https://doi. org/10.1056/NEJMra1301758.

Tarlo SM [2016]. Update on work-exacerbated asthma. Int J Occup Med Environ Health 29(3):369-374, https://doi.org/10.13075/ijomeh.1896.00676.

Thomas KE, Trigg CJ, Baxter PJ, Topping M, Lacey J, Crook B, Whitehead P, Bennett JB, Davies RJ [1991]. Factors relating to the development of respiratory symptoms in coffee process workers. Br J Ind Med 48(5):314-322, https://doi.org/10.1136/oem.48.5.314. 
This page left intentionally blank 
Keywords: NAICS 311920 (Coffee roasting), Wisconsin, diacetyl, 2,3-pentanedione, 2,3-hexanedione, flavorings, coffee, carbon monoxide, carbon dioxide, volatile organic compounds (VOCs). 


\section{NIOSH Health Hazard Program Description}

The Health Hazard Evaluation Program investigates possible health hazards in the workplace under the authority of the Occupational Safety and Health Act of 1970 (29 U.S.C. § 669(a) (6)). The Health Hazard Evaluation Program also provides, upon request, technical assistance to federal, state, and local agencies to investigate occupational health hazards and to prevent occupational disease or injury. Regulations guiding the Program can be found in Title 42, Code of Federal Regulations, Part 85; Requests for Health Hazard Evaluations (42 CPR Part $85)$.

\section{Disclaimer}

The recommendations in this report are made on the basis of the findings at the workplace evaluated and may not be applicable to other workplaces.

Mention of any company or product in this report does not constitute endorsement by the National Institute for Occupational Safety and Health (NIOSH).

Citations to Web sites external to NIOSH do not constitute NIOSH endorsement of the sponsoring organizations or their programs or products. NIOSH is not responsible for the content of these Web sites. All Web addresses referenced in this document were accessible as of the publication date.

\section{Acknowledgments}

Desktop Publisher: Barbara Elbon

Data Analysis Support: Nicole Edwards, Kathleen Fedan, and Brian Tift

Laboratory Support: Michael Aldridge, Dru Burns, Ryan LeBouf, Tia McClelland, Yeonmi Park, Anand Ranpara

Site Visit Team Members: Mike Beaty, Randy Boylstein, Valeria Fonti, Alyson Fortner

\section{Availability of Report}

Copies of this report have been sent to the employer and employees at the facility. The state health department and the Occupational Safety and Health Administration Regional Office have also received a copy. This report is not copyrighted and may be freely reproduced.

This report is available at http://www.cdc.gov/niosh/hhe/reports/pdfs/2018-0134-3373.pdf.

All other Health Hazard Evaluation Reports may be found at https://www2a.cdc.gov/hhe/ search.asp.

\section{Recommended citation for this report:}

NIOSH [2020]. Health hazard evaluation report: Evaluation of exposures at a coffee roasting, flavoring, and packaging facility. By Fortner AR, Beaty MC. Morgantown, WV: U.S. Department of Health and Human Services, Centers for Disease Control and Prevention, National Institute for Occupational Safety and Health, NIOSH HHE Report No. 2018-0134-3373. 
Delivering on the Nation's promise:

Safety and health at work for all people through research and prevention

To receive documents or other information about occupational safety and health topics, contact NIOSH

Telephone: 1-800-CDC-INFO (1-800-232-4636)

TTY: 1-888-232-6348

email: cdcinfo@cdc.gov

or visit the NIOSH website at http://www.cdc.gov/niosh

SAFER • HEALTHIER - PEOPLE ${ }^{\text {TM }}$ 